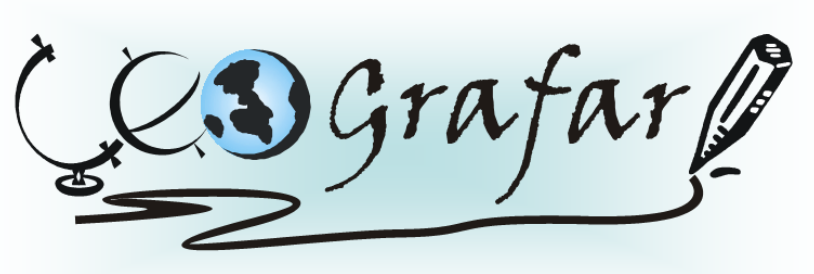

Revista Eletrônica do Programa de Pós-Graduação em Geografia - UFPR

\title{
ALUÍSIO AZEVEDO E O DETERMINISMO SOCIAL NA CONSTRUÇÃO DO ESPAÇO URBANO: REFLEXÕES À LUZ DA GEOGRAFIA HUMANISTA E CULTURAL
}

ALUÍSIO AZEVEDO AND SOCIAL DETERMINISM IN THE CONSTRUCTION URBAN SPACE: READERS IN THE LIGHT OF HUMANIST AND CULTURAL GEOGRAPHY

(Recebido em 06-01-2016; Aceito em 31-01-2017).

Jorgeanny de Fátima Rodrigues Moreira

Doutoranda em Geografia na Universidade Federal de Goiás jorgeannyf@gmail.com

\section{Resumo}

Nesse artigo propõe-se a leitura das três mais importantes obras de Aluísio Azevedo, 0 Cortiço, Casa de Pensão e O Mulato, a partir da geografia humanista e cultural. Com base em uma análise voltada para os aportes teórico-conceitual do existencialismo sartreano far-se-á um contraponto à literatura de Azevedo, que foi influenciada pelo cientificismo, darwinismo e determinismo social. Nas obras listadas o autor descrevia a degradação do meio urbano brasileiro, em que a miséria e a pobreza eram grandes responsáveis pela degradação moral do homem. Em decorrência, atitudes ligadas a violência, promiscuidade e vícios justificavam-se pela natureza das relações sociais no espaço degradado. Com isso pretende-se contribuir com reflexões acerca da produção do espaço urbano e social brasileiro, e as explicações científicas a que eram dadas na época, em que o positivismo e o cientificismo apresentavam um sentido generalizado nas ciências e na literatura do país. A interpretação, aqui exposta, a partir das leituras de Jean-Paul Sartre tem o intuito de explicar os conflitos sociais a partir do homem, em detrimento do meio. Levar-se-á em consideração as ações humanas como próprios de suas experiências e essência, ao contrário da literatura naturalista que considera a "natureza" humana. Tal estudo foi subsidiado, por uma metodologia qualitativa de teor descritiva e analítica.

Palavras-Chave: Espaço urbano; Cientificismo; Determinismo; Existencialismo.

\section{Abstract}

In this paper we propose the reading of the three most important works of Aluísio Azevedo, 0 Cortiço, Casa de Pensão and O Mulato, from the humanistic and cultural geography. Based on the analysis focused on the theoretical and conceptual contributions of Sartre existentialism, we will do a 
counterpoint to Azevedo literature, and the influence by scientism, Darwinism and social determinism. In the works listed, the author described the degradation of the brazilian urban space, describing the poverty urban space and the responsibility for the moral degradation of man. As a result, attitudes related violence, promiscuity and defects justified by the nature of social relations in the degraded space. With this, we intend pitch in with reflections on the production of brazilian urban and social space, and scientific explanations that were given at the time, where positivism and scientism had a general sense in the sciences and in the country's literature. The interpretation that we do, from JeanPaul Sartre's reading is in order to explain social conflicts front the man at the expense of the environment. We will take into consideration human actions as their own experiences and essence, unlike the naturalistic literature that considers the human "nature". That study was funded by a qualitative methodology of descriptive and analytical read.

Keywords: Urban space; Scientism; Determinism; Existentialism

\section{Introdução}

A geografia, em especial a humanista e cultural, utiliza descrições artísticas como ilustrações para seus trabalhos, com ênfase as literárias (MARANDOLA JR, 2010). Segundo Moreira (2016), as fundamentações teórico-metodológicas da geografia cultural são de caráter essencialmente humanista, podendo apresentar em seu embasamento filosófico a fenomenologia e o existencialismo. Os romances da literatura brasileira possibilitam para a geografia uma compreensão do espaço, ao descrevê-lo em seus aspectos políticos, culturais, sociais e econômicos, e isso pode ser realizado ao aproximá-los pelo viés do existencialismo sartreano, que permite ler as marcas da existência humana no espaço social.

Com isto posto, ao propor a leitura de textos literários pelo viés da geografia humanista e cultural, pretende-se, além de colaborar com uma metodologia interdisciplinar, ampliar a reflexão geográfica e o conteúdo teórico-conceitual e metodológico para essa disciplina. As obras selecionadas para esse estudo são O Mulato, Casa de Pensão e O Cortiço de Aluísio Azevedo, uma vez que esse romancista faz uma importante leitura do Brasil do final do século XIX em todos os aspectos acima elencados.

Ao estudar essas obras é possível identificar um país estratificado em classes sociais, amparado em contradições e desigualdades, com grande clamor popular - em especial as classes oprimidas e de alguns intelectuais -, por uma reforma política, a partir da instauração da República e 0 fim do trabalho escravo. Para tanto, o autor dessas obras descreve o cotidiano em duas cidades, em regiões importantes do ponto de vista econômico na época, mas com aspectos culturais bastante distintos: Rio de Janeiro e São Luís no Maranhão.

O Mulato - cujo enredo tem como espaço São Luis -, retrata aspectos relacionados à sociedade baseada no trabalho escravo; na formação de uma pequena burguesia agrária e comercial amparada na exploração e opressão do trabalho de imigrantes e negros; uma vida urbana ainda 
incipiente com forte vínculo na economia agrária; a modernização do espaço urbano com investimentos em meios de transportes e comunicação como portos, ferrovias e estradas. Nas obras Casa de Pensão e $O$ Cortiço, o autor não se absteve em tecer críticas à política e à sociedade burguesa, além dos aspectos já esmiuçados em O Mulato, Aluísio Azevedo aprofundou-se nas desigualdades e nos atores sociais envolvidos no processo de construção e produção do espaço urbano brasileiro.

Nas três obras, é perceptível a ambivalência do espaço urbano, já que as diferentes classes sociais conviviam lado a lado, reforçando a contradição de uma teoria determinista. Identifica-se nos romances estudados tal realidade a partir da tensa e conflituosa convivência entre o rico e o pobre, 0 explorador e o explorado, o mulato e o branco, o imigrante europeu e 0 brasileiro, o senhor e 0 escravo.

Com base nessas premissas, a geografia subsidia uma leitura do espaço urbano em suas nuances, suas características e a sua produção a partir dos atores sociais que o produz, e que o vivem cotidianamente. As descrições presentes na narrativa dos romances vislumbram as sociedades da metade do século XIX. Muitos desses aspectos revelam-se atuais, em especial as relações e estratificações sociais historicamente construídas, e ajudam compreender fatores importantes para a produção do espaço social brasileiro, quando o autor dessas obras intensifica o seu olhar para 0 homem e a sua transformação pelo meio.

O determinismo social surge nessas discussões como uma fundamentação teórica e científica de Aluísio Azevedo para analisar o surgimento dos novos espaços que se formavam nos dois centros urbanos analisados. As teorias empregadas pelo romancista, na tentativa de explicar a realidade brasileira, foram importadas da Europa. Apesar de chegarem com atraso, o positivismo, o cientificismo, 0 darwinismo e o determinismo social foram estudados e adaptados para o ponto de vista nacional, promovendo o preconceito e a ideia de inferioridade do povo que participou da construção do território nacional.

O racismo e a discriminação social eram padrão de conduta, não mais motivado pela igreja e pelo cristianismo, mas pelo deslumbramento antropocêntrico da ciência moderna (SERÉN, 1997). E o círculo intelectual brasileiro, ao assumir as teorias nascidas na Europa confrontava com o sentido de identidade nacional e cultural do país. Isso promove um atraso nas discussões acerca de referenciais para a construção identitária, mas é frutífero para o campo da literatura brasileira, quando surge 0 realismo e o naturalismo, o primeiro liderado por Machado de Assis e o segundo por Aluísio Azevedo.

Com o auxílio da metodologia qualitativa de base interpretativa e analítica, será desenvolvido algumas reflexões acerca dos três romances citados. Objetiva-se, com isso, contribuir com uma leitura da construção do espaço urbano, com foco nos seus aspectos sociais e culturais, em que o homem é o 
principal responsável. Além disso, pretendemos elaborar uma síntese dos elementos que possibilitaram a constituição das estruturas sócio-espaciais, a partir da geografia e da literatura.

\section{Materiais e Métodos}

Com base na metodologia qualitativa, em sua perspectiva interpretativa, três romances de Aluísio Azevedo são analisados, tanto como objeto de pesquisa como conteúdo bibliográfico, pois em sentido correlacional busca-se explorar as reações entre as obras estudadas e o espaço geográfico. A pesquisa contará ainda com uma leitura analítica, uma vez que envolve o estudo e avaliação de conteúdo literário para explicar um fenômeno.

Para a acuidade na análise das informações, essencialmente importantes para a interpretação dos fenômenos e a sua correlação com a ciência geográfica, foi utilizado a análise de conteúdo. De acordo com Bardin (2011) é necessário estabelecer quadros e diagramas dos fenômenos que coloquem em evidência as informações com conteúdos que possam ser correlacionados. O processo é finalizado com a interpretação daquilo que representa o significado esperado, ou seja, as descrições geográficas nos textos literários.

Inicialmente, foram selecionadas as obras que abarcavam os fenômenos geográficos estudados, em seguida foi realizado a leitura e os diagramas contendo as informações que seriam consideradas para interpretação, como a construção do espaço urbano, o cientificismo e 0 determinismo social presente nas obras literárias. Por último, o confronto com o método de análise e as referências filosóficas de cunho existencialista, mediante o referencial teórico sartreano. Com base nessas informações, algumas considerações sobre os textos selecionados foram criteriosamente analisadas.

Em 1881 Aluísio Azevedo publica O Mulato, obra a qual delineia as primeiras críticas ao Império, ao partido conservador, ao clero e ao modelo social da época. Essa obra causa polêmica na sociedade maranhense tendo em vista o seu principal tema: o preconceito racial. Todavia, esse romance foi um grande sucesso na corte, onde o círculo intelectual brasileiro despontava suas primeiras críticas ao modelo social e político do país, e demonstrava fascínio pela corrente científica em voga: o positivismo. Assim sendo, Aluísio Azevedo retorna ao Rio de Janeiro em 1881 e inicia a publicação de seus romances nos folhetins dos jornais (ABL, 2015).

No Rio de Janeiro, o escritor transforma em romances uma nova preocupação que surge a partir de suas observações e análises: os agrupamentos humanos (estalagens, pensões, cortiços), a degradação humana dos indivíduos que vivem nesses espaços e a exploração dos pobres pelos mais 
ricos. Essas preocupações resultam-se em duas obras, consideradas os seus melhores romances pelos críticos literários da época: Casa de Pensão (1884) e 0 Cortiço (1890).

Assim como em 0 Mulato, esses dois últimos romances apresentaram críticas políticas e sociais. Aluísio Azevedo descrevia, por meio de suas personagens, o seu descontentamento com a monarquia, os conservadores, a escravidão e a exploração a que eram submetidos os mais pobres. Almeida (2011: 15), explica que o Estado era um dos alvos do romancista. Segundo o estudioso da obra de Aluísio Azevedo:

O Estado aparece em dois momentos em 0 Cortiço: frente aos pobres como polícia que invade o cortiço, frente aos ricos agraciando-os com títulos e honrarias. Assim é que Aluísio imprime sua crítica: o Império polícia os pobres enquanto nobilita os ricos.

Mas, a figura do Estado não surge como um dos motivadores ou produtores da desigualdade social apenas em O Cortiço. Igualmente em O Mulato e Casa de Pensão, Azevedo evidencia as fraquezas estruturais da política conservadora e monárquica, demonstra a sua simpatia pelos ideais republicanos, sua aprovação ao movimento abolicionista e a sua aversão ao clero.

Em O Mulato, o filho de uma escrava, com um burguês de origem portuguesa, representa as ideias revolucionárias do escritor contrastando com a personagem que figura o clero, o cônego Diogo, um sacerdote corrupto, assassino e que usa sua posição para alienar e manipular a classe burguesa de São Luis no Maranhão. A primeira personagem - o protagonista - anuncia a simpatia de Aluísio Azevedo ao abolicionismo, ao republicanismo, enquanto o segundo - a principal figura religiosa da província -, desperta todo o seu desprezo à influência da Igreja Católica sobre à sociedade e ao governo. Nesse romance, Azevedo compara, por meio de metáforas, as suas personagens às próprias convicções e contestações ao modelo social vigente:

Por esse tempo aqueles três surgiam na rua, formando cada qual mais vivo contraste com os outros: Manuel no seu tipo pesado e chato de negociante, calças de brim e paletó de alpaca; o cônego imponente na sua batina lustrosa, aristocrata, mostrando as meias de seda escarlate e o pé mimoso, apertadinho no sapato de polimento; Raimundo, todo europeu, elegante, com uma roupa de casimira leve, adequada ao clima do Maranhão, escandalizando o bairro comercial com o seu chapéu-de-sol coberto de linho claro e forrado de verde pela parte de dentro. Formavam, dizia este último, chasqueando, sem tirar o charuto da boca uma respeitável trindade filosófica, na qual, ali, o Sr. Cônego representava a teologia, o Sr. Manuel a metafísica, e ele, Raimundo, a filosofia positiva, o que, aplicado à política, traduzia-se na prodigiosa aliança dos três governos 0 do papado, 0 monárquico e 0 republicano! (2001: 98) 
Azevedo realça sua predileção à última personagem que representa os pensamentos liberais e republicanos, ao positivismo e ao seu ideal político: a república. Demonstra ainda fascínio pela ciência positivista que chegara com quase vinte anos de atraso no Brasil, concorda com a valorização da cultura importada da Europa e narra o seu descontentamento com o atraso científico e intelectual de seu país.

O autor inova e escandaliza a sociedade com os seus ideias revolucionários ao tornar protagonista - culto, rico, elegante, educado por instituições europeias -, um mulato, filho de uma escrava com um burguês de origem europeia, personagens que representavam a concepção determinista e darwinista adotada pelo autor: a raça inferior curva-se à superior. Ademais, evidencia em seus escritos a busca pela miscigenação como forma do branqueamento, uma tentativa de melhoramento da raça.

Em O Mulato, Aluísio Azevedo consagra a sua escrita naturalista, com forte influência da ciência positivista, do determinismo e darwinismo social ${ }^{1}$, e será em 0 Cortiço que ela será mais agraciada pela crítica literária e pelos intelectuais da corte. Isso se deve ao amadurecimento intelectual e político do autor, que começa a anunciar a sua preocupação acerca das estruturas urbanas cariocas, já iniciadas em Casa de Pensão. Isso porque os romances de Aluísio Azevedo são contemporâneos as suas próprias vivências no Maranhão e no Rio de Janeiro, na segunda metade do século XIX. Nesse período, a economia brasileira é baseada no setor latifundiário, em que a oligarquia agrária determina as estruturas socioeconômicas do Brasil. O modelo econômico, portanto, baseia-se em uma monocultura da exportação, da supervalorização da produção do café e calcado na mão de obra escrava (DIAS, 2010).

A partir da década de 1870, o tráfico negreiro não mais é permitido, surge a figura do trabalhador imigrante, que vai aos poucos substituir os escravos por meio do trabalho assalariado.

\footnotetext{
1 É importante frisar que ao que pode parecer, sob o ponto de vista das correntes filosóficas e científicas contemporâneas, essas teorias são ultrapassadas, desfavorecem e inferiorizam diversas classes sociais, inclusive aquelas que foram subjugadas por séculos em nosso país. Além disso, salientamos que não concordamos com muitas teorias expostas e defendidas pelo autor das obras analisadas, porém essas eram as correntes filosóficas e científicas em voga na época, e que tentavam explicar a realidade sob um ponto de vista eurocêntrico. Os cientistas e intelectuais brasileiros do século XIX tentaram adaptar essas teorias à realidade da nossa sociedade, constituída majoritariamente por raças consideradas inferiores pelas teorias a que esses estudiosos eram adeptos. Na tentativa de adaptar essas teorias a nossa realidade, diversos cientistas e intelectuais incorporaram a teoria do branqueamento, em seus estudos e análises sociais, como uma "salvação" da inferioridade da raça brasileira, e isso se comprova com as personagens (das obras estudadas, como Rita Baiana e Bertoleza em 0 Cortiço, Domingas em 0 Mulato e Coqueiro em Casa de Pensão) negras e/ou brasileiros que buscam relacionamentos com brancos e/ou europeus. $\mathrm{Na}$ literatura, a influência de teorias como o determinismo, cientificismo e darwinismo deturpou a busca pela identidade nacional. O Naturalismo, escola literária em que se enquadra Aluísio Azevedo, não apresenta a caracterização ou a tentativa de representar uma identidade nacional, ao contrário do Romantismo que privilegiou a figura do índio e do branco europeu descartando o negro. A literatura, assim como outras manifestações artísticas desse período, demonstrou-se preconceituosa e só buscou reparar-se a partir da década de 1930, em que os negros passam a co-protagonizar as narrativas brasileiras (LIMA, 2014).
} 
Vassalo (2009) explica que nesse mesmo período, há evidências da transformação e modernização do aparato tecnológico e das estruturas urbanas no país. Com a industrialização, prioritariamente cafeeira no estado de São Paulo, aparecem fábricas, intensifica-se o comércio, inicia-se a construção de ferrovias.

A insatisfação da burguesia e da classe média insurgente com os partidos Liberal e Conservador abre espaço para a popularidade do Partido Republicano que tinha como luta 0 abolicionismo, o fim da monarquia e a instauração de um Estado laico. Aluísio Azevedo aderiu aos ideais republicanos e levantou a bandeira destas lutas em seus romances.

A aplicação de pensamentos científicos na literatura não principiou-se com Aluísio Azevedo, mas foi ele quem importou esse conceito da escola francesa. De fato quem iniciou a experimentação e o cientificismo na literatura foi Émile Zola na França que, segundo Almeida (2011: 5) "tinha por definição a estratégia de transformar a atividade literária em uma atividade experimental com o objetivo principal de analisar a realidade segundo a observação do homem em seu meio e momento".

Portanto, para Zola assim como o médico ou o químico, o escritor precisa por a prova com base em experimentações as suas impressões coletadas em campo. E só após, submetê-la ao público em forma de um romance experimental. Émile Zola seguia os princípios deterministas e cientificistas que tanto inspirou a literatura de Aluísio Azevedo e propunha os experimentos em campo para comprovar que o meio influencia na formação do homem. Nas palavras de Zola

O objetivo do método experimental, o termo de toda pesquisa científica é, portanto, idêntico para os corpos vivos e para os corpos brutos: consiste em encontrar as relações que prendem um fenômeno qualquer à sua causa próxima, ou em outras palavras, em determinar as condições necessárias à manifestação desse fenômeno. A ciência experimental não deve se preocupar com o porquê das coisas; ela explica como, e nada mais (1979: 27).

As explicações do escritor possibilitam a compreensão acerca das raízes do naturalismo, tendência em que se enquadram as obras de Aluísio Azevedo. Além disso, contribuem para contrapôlas pelo pensamento de Sartre que identifica o porquê e o como por meio e fim. Segundo esse filósofo, 
se fizéssemos como Zola e declarássemos que eles assim são devidos à hereditariedade, por influência do meio, da sociedade, por um determinismo orgânico ou psicológico, todos se traquilizariam e diriam: aí está, somos assim e ninguém pode fazer nada; o existencialista, porém quando descreve um covarde, afirma que esse covarde é responsável por sua covardia. Ele não é assim por ter um coração, um pulmão ou um cérebro covardes; ele não é assim devido a uma qualquer organização fisiológica; mas é assim porque se construiu como covarde mediante seus atos. Não existe temperamento covarde; existem temperamentos nervosos, existem pessoas que têm "sangue fraco" como diz o povo; ou temperamentos ricos; mas o homem que tem sangue fraco nem por isso é um covarde, pois o que cria a covardia é o ato de renunciar ou de ceder: o temperamento não é um ato e o covarde se define pelos atos que pratica (1970: 12).

Assim, Sartre desmistifica a qualidade do meio em influenciar o caráter do homem, característica narrada e descrita pelos naturalistas. Ao propor que o meio tem papel determinante nas ações do indivíduo, o cientificismo desconsidera a construção da subjetividade e essência humana, descarta todas as possibilidades de uma mudança social baseada nas ações e atitudes ligadas a intersubjetividade do sujeito.

Todavia, o aspecto mais marcante das obras literárias desse período, e que contribui com a leitura espacial brasileiro, é a crítica social baseada na institucionalização de algumas forças hegemônicas de poder. Os enredos dos romances naturalistas são ambientados em um espaço urbano degradado pela miséria, e corrompido pelas forças políticas conservadoras. Porém, as estórias, como próprio do positivismo, explicar-se-iam como tais fenômenos aconteciam, mas não bebiam em suas fontes, ou seja, nas raízes dos problemas para a compreensão de suas causas, que para Sartre (1970) seriam os meios.

Por não romper com os modelos de literatura baseadas nessas vicissitudes, Dias (2010) não compreende o Naturalismo como uma escola literária, mas como uma tendência ou uma ramificação do Realismo, pois o primeiro apoia-se nesse último para aprofundar suas características. Enquanto que no Realismo existem romances, como aqueles escritos por Machado de Assis, em que a narrativa perpassa o cotidiano da burguesia - em sua vida social baseada em visitas aos teatros, às casas de jogos e outros ambientes nobres -, no Naturalismo de Aluísio Azevedo a preocupação literária está calcada no preconceito racial (O Mulato), na ascensão social dos imigrantes, a exploração dos pobres pelos mais ricos e a luta de classes (Casa de Pensão e O Cortiço).

As personagens centrais são figuras comuns, exploradas, subjugadas e entregues aos destinos das políticas conservadoras, da economia excludente e das paixões humanas. Esta última, caracterizada por Aluísio Azevedo, como motivadora da desgraça e mudança de comportamento do homem. Para Sartre (1987), as paixões humanas se encontram no campo das emoções e da 
experiência, as quais compreendem a existência do homem. Enquanto afeto, isto é, afetar a emoção do outro é um ato e advém das condutas e valores, que podem ser boas ou más, depende da sua essência, mas nunca da sua existência, porque, o homem, primeiro, existe; se descobre; aparece no mundo; e somente depois se define. Portanto, as paixões humanas não podem definir suas ações, elas já estão constituídas por ele mesmo.

Mas, no naturalismo as experiências e a subjetividade não eram consideradas. Ao contrário do Realismo, cuja preocupação com a construção psicológica das personagens é uma constante, caracterizada por indivíduos complexos, com intensos embates psicológicos na busca pela compreensão da condição humana. No Naturalismo, a complexidade da vida humana não é importante, não há uma análise acerca do comportamento humano, o que importa é o meio, as causas externas ao homem como fatores preponderantes em suas ações, comportamentos e atitudes. 0 homem é fruto de seu meio, e este último que deve ser estudado e compreendido.

Dias (2010: 93) complementa que "enquanto o realismo strictu sensu volta seus olhos para uma parcela da sociedade que pode frequentar teatros e óperas, o Naturalismo se volta para o cortiço e para a casa de pensão". Portanto, enquanto no primeiro, as personagens recebem uma descrição profunda, inclusive de suas características psicológicas, no segundo, isso não ocorre, uma vez que a descrição é sobre o coletivo, o povo, o indivíduo e sua identidade é invisível frente a sociedade (meio) que o engloba.

Coutinho (2004: 11) explica que o "Realismo se tingirá de Naturalismo, no romance e no conto sempre que fizer personagens e enredos se submeterem ao destino cego das 'leis naturais' que a ciência da época julgava ter codificado". No entanto, há aspectos que afastam o Naturalismo do Realismo, o tornando uma escola literária independente, com características próprias e autênticas. 0 Realismo, sob a influência também da escola francesa liderada por Gustave Flaubert, se caracteriza pela observação e análise dos fatos. A análise social é feita a partir do indivíduo, do comportamento humano, com rigorosa observação psicológica. As obras são construídas a partir da descrição e da narrativa sobre situações que envolvem a burguesia urbana, de forma a tecer críticas sobre os comportamentos das personagens que pertencem a essa classe social.

O Naturalismo abarca uma análise "de fora para dentro", ou seja, a tendência é que as personagens são condicionadas, produtos do meio e dos fatores sociais, históricos e biológicos. As obras, nesse estilo literário, partem de uma análise das camadas inferiores da sociedade, as personagens são figuras do proletariado, são os indivíduos marginalizados. 
Observa-se que ao contrário do Realismo, no Naturalismo a influência do espaço sobre o comportamento das personagens é descrito com maior afinco. Sobre isso, dois trechos, que entre tantos outros, comprovam essa afirmação:

0 português abrasileirou-se para sempre; fez-se preguiçoso, amigo das extravagâncias e dos abusos, luxurioso e ciumento; fora-lhe de vez o espírito da economia e da ordem; perdeu a esperança de enriquecer, e deu-se todo... (AZEVEDO, 1890: 202)

E acrescenta:

A cadeia continuava e continuaria interminavelmente; o cortiço estava preparando uma nova prostituta naquela pobre menina desamparada (AZEVEDO, 1890: 175).

Portanto, os hábitos e os costumes vivenciados no cortiço influenciaram as mudanças comportamentais dessas duas personagens que eram no início da estória, indivíduos honestos, dignos e preocupados com a índole frente aos demais moradores. Mas, ao viver sob os hábitos dos brasileiros pobres e desprovidos de educação tornaram-se preguiçosos e "entregues" à própria sorte.

$O$ determinismo, sob a égide do cientificismo serve como pano de fundo, para desenhar as personagens e o espaço onde é ambientado o enredo. 0 ambiente e as circunstâncias externas determinam a "natureza" do homem. O comportamento humano é determinado pelos fatores biológicos, sociológicos e ambientais, inclusive a razão está condicionada aos fenômenos externos.

Deveras que, as ideias de Comte, Spencer, Darwin e Haeckel conquistaram a classe intelectual brasileira que deixou para trás a subjetividade e as preocupações espiritualistas e psicológicas do indivíduo (SILVA, 2010). E conforme já mencionado, e ao citar Sartre, as ideias referentes a "existência", em detrimento da "natureza" humana são acatadas. Afinal, ao associar a vida à natureza, assumiu-se a passividade frente ao outro e ao meio, descartando a responsabilidade frente ao mundo e destituindo sua capacidade de "ser-no-mundo".

Todavia, não pode-se desprezar a importância da obra de Aluísio Azevedo para a literatura e as ciências sociais e humanas no Brasil. Veríssimo (1995: 142), assim descreve o escritor Aluísio Azevedo e as suas obras: "Os romances a Casa de Pensão (1884), O homem (1887), O cortiço (1890), confirmaram o talento afirmado no Mulato e asseguraram-Ihe na nossa literatura o título de iniciador do naturalismo e do seu mais notável escritor". Quanto ao estilo naturalista, Veríssimo (1995: 142) não só o distingue e o separa do Realismo como ainda afirma: 
Os seus assuntos prediletos, o seu objeto, os seus temas, os seus processos, a sua estética, tudo nele estava ao alcance de toda a gente, que se deliciava com se dar ares de entender literatura discutindo de livros que traziam todas as vulgaridades da vida ordinária e se the compraziam na descrição minuciosa. Foi também o que fez efêmero o naturalismo, já moribundo em França quando aqui nascia. Não seria, porém, justo contestarIhe o bom serviço prestado, tanto aqui como lá, às letras. Ele trouxe à nossa ficção, o mais justo sentimento da realidade, arte mais perfeita da sua figuração, maior interesse humano, inteligência mais clara dos fenômenos sociais.

Apesar do curto período em que esteve em voga, o Naturalismo deixou heranças, não apenas para as Letras e a Literatura, mas também para as ciências sociais, com temas profícuos na atualidade. E o principal autor dessa tendência literária no Brasil, Aluísio Azevedo, deixou como legado as descrições sobre a vida urbana do século XIX, a miséria dos grupos sociais menos privilegiados, a exploração do pobre pelo rico, a luta de classes, a estrutura urbana em decadência no período imperial, e a urgência de uma reforma política que jazia pela Proclamação da República, a negação do conservadorismo calcado na oligarquia cafeeira e na produção baseada no trabalho escravo.

Ademais, os temas apresentados nas estórias de Aluísio de Azevedo servem de contributo à geografia ao agregar, nas descrições detalhadas, a ocupação territorial dos imigrantes, a construção do espaço urbano a partir da junção das diversas classes de trabalhadores, a reprodução da cultura do povo brasileiro no espaço, as paisagens construídas a partir da cultura, a ideia de lugar partindo das relações sociais estabelecidas entre as personagens, e tantos outros temas e conceitos geográficos que Aluísio Azevedo descreve, sem assim o pretender.

\section{Resultados e Discussão}

Um fato que caracterizou a vida política e cultural do espaço urbano brasileiro do século XIX foi o "movimento intelectual da geração de 1870", cujo agrupamento de indivíduos, com afinidades ideológicas e científicas, contribuiu para o nascimento de preocupações próprias da vida urbana, e que foi tão bem descrita por Aluísio Azevedo.

Alonso (2000) explica que em fins do Império formou-se um grupo de intelectuais cujo movimento interessava-se mais em copiar ou imitar aquilo que era produzido na Europa, do que entender ou analisar de fato a realidade nacional. A autora nomeia o movimento como reformista, uma vez que eles visavam reformas no modelo político monárquico e na economia. "Os 'intelectuais' da crise do Império não visavam produzir obras de valor universal, mas interpretações do Brasil" (ALONSO, 2000: 45). 
A crítica da autora é válida ao passo que as correntes científicas e filosóficas nascidas na Europa apresentavam um contexto específico, com leituras da sociedade europeia, que já vivia desde o século XVIII uma experiência intensa de urbanização, de industrialização, da intensificação do trabalho operário e da expulsão do homem do campo para as cidades.

Ademais, os países em que deram origem a estas principais teorias, França, Portugal e Inglaterra, já enfrentavam um longo processo no aumento da miséria ao gerar uma classe operária desprovida de condições básicas de saúde, moradia, saneamento básico e educação. A agitação política e os embates entre as classes sociais eram grandes. $E$ os expoentes do naturalismo na Europa, Gustave Flaubert, Émile Zola, Honoré de Balzac e Eça de Queiroz, manifestavam o interesse por reforma social a partir das denúncias, dos problemas sociais da época, em seus textos literários (VERÍSSIMO, 1995).

As teorias que surgiam para a compreensão desses fenômenos eram adaptadas pela "geração de intelectuais de 1870" para explicar os contextos políticos, sociais e culturais no Brasil, ou seja, buscavam respostas para os dilemas da sociedade brasileira - entre eles o sistema escravocrata, 0 modelo político baseado ainda nos moldes colonialista e 0 incipiente modelo assalariado, que substituía o trabalho escravo gradativamente pela figura do imigrante -, no cientificismo e no positivismo.

Entre esses intelectuais enquadra-se Aluísio Azevedo que seguindo uma lógica empírica, positivista, determinista e darwinista tentava interpretar e explicar os fenômenos observados. Assim como Émile Zola na França, o romancista brasileiro narrava suas estórias com base em experimentações, ou seja, a partir de extensas observações, transformava fatos reais em relatos ficcionais. Daí os romances 0 Mulato que refere-se à discriminação racial à pequena burguesia vinculada à economia agrária da sociedade maranhense; Casa de Pensão, baseado em um crime que mobilizou a imprensa carioca em finais da década de 1870, fato explicado pela influência do meio degradado, pela violência e miséria, nas atitudes e comportamentos de um jovem estudante de origem aristocrática; e O Cortiço referência à sua observação e participação incisiva nas habitações coletivas da classe operária carioca.

Esse último romance citado foi influenciado - talvez remodelado² as mãos de Aluísio Azevedo ao substituir as imagens e personagens franceses pelos brasileiros -, pela obra L'assommoir de Émile

\footnotetext{
${ }^{2}$ Afirmamos isso devido a semelhança entre as duas estórias. Ambas possuem como protagonista uma moradia coletiva, em que a degradação social, exploração, pobreza, miséria e promiscuidade influenciavam a mudança dos comportamentos e atitudes dos moradores que chegavam ao lugar. As duas obras explicitam a realidade de exploração a que eram submetidos os operários, negros e imigrantes, além da riqueza de uns por meio da subjugação do outro. Exemplos de degradação humana também são os mesmos: prostituição, homicídios, alcoolismo, roubos e loucura. Observa-se que a obra de Émile Zola foi produzida em 1877, 13 anos antes da publicação de O Cortiço, portanto, as teorias do cientificismo e
} 
Zola publicado em 1877, que caracteriza um bairro operário da França industrial, estratificada em classes sociais que vivem embates promovidos pela intensa desigualdade: a burguesia foi representada pelos industriais, e os operários pelos moradores das habitações coletivas localizadas na periferia parisiense.

Nota-se uma diferença entre a obra brasileira e a francesa que a inspirou, pois na França do século XIX, os pobres operários viviam em bairros afastados daqueles centrais e nobres ocupados pela burguesia e pela aristocracia. Já nesse período surgem as chamadas periferias em detrimento dos bairros nobres. Ao contrário da realidade brasileira em que os pobres e os ricos conviviam em um mesmo espaço - o centro urbano -, o que evidenciava a exclusão era a natureza de degradação e miséria dos alojamentos, e o comportamento de seus moradores.

Para a produção de $O$ Cortiço, Aluísio Azevedo realizou suas experimentações nas habitações coletivas $^{3}$ cariocas, muito comuns a partir da segunda metade do século XIX em função do desenvolvimento urbano e industrial. Os trabalhadores operários, escravos libertos, imigrantes nacionais e estrangeiros buscavam as áreas centrais onde concentravam-se os locais de trabalho e os principais meios de transporte. De acordo com Vaz (1994: 582)

A necessidade de moradias baratas para trabalhadores, a limitada disponibilidade de construções para atender a esta demanda, os altos aluguéis, a possibilidade de obtenção de bons rendimentos por parte dos privilegiados proprietários e arrendatários de prédios e terrenos são fatores que fizeram com que se multiplicassem estas moradias.

Não obstante, esse tipo de moradia aparece em duas obras de Aluísio Azevedo. Em Casa de Pensão, há a descrição de um prédio de dois andares em estilo colonial, uma típica edificação burguesa na Rua Resende em região central do Rio de Janeiro. Esse sítio pertenceu a uma família que enriquecera com o tráfico negreiro, mas que entregou-se à falência assim que o negócio foi proibido. 0 prédio foi readequado para uma habitação coletiva, em que os habitantes a escolhiam pela localização, pelo fácil acesso aos principais meios de transporte e ao trabalho. Apesar de coletiva, a pensão acolhia

o naturalismo chegam com atraso ao Brasil, mas não desprende da realidade social do país, cuja produção sócio-espacial urbana começa a eclodir e mostrar seus malefícios à população nesse período.

${ }^{3}$ Nessas habitações viviam negros alforriados que desenvolviam atividades profissionais variadas, imigrantes empregados em atividades assalariadas e que substituíam gradativamente os escravos, prostitutas, pequenos comerciantes, lavadeiras. Esses lugares eram ocupados por aqueles que pertenciam a mais baixa escala hierárquica da sociedade brasileira. Eram caracterizados como violentos, preguiçosos para o trabalho, festeiros, estavam sempre dispostos para o samba e para a capoeira. Esses conjuntos habitacionais deram origem aos espaços hoje conhecido como favelas, iniciadas com a demolição dos cortiços no final do século XIX - como mecanismo de higienização proposto pelo prefeito Barata Ribeiro -, seus antigos moradores aproveitaram os materiais resultantes da demolição para a construção de barracões nos morros do entorno do centro urbano do Rio de Janeiro. 
sujeitos considerados "dignos", com bom emprego e profissão: artistas plásticos, músicos, artesãos, estudantes, advogados e caixeiros imigrantes.

Em O Cortiço, as habitações acolhiam aqueles menos privilegiados, que não possuíam outra opção de moradia além daqueles cômodos com banheiros compartilhados. Ali alojavam-se escravos alforriados, imigrantes - que ocupavam as funções que outrora pertenciam aos negros -, prostitutas e lavadeiras. Nessa obra, o autor descreveu a miséria e o descaso em que esses sujeitos eram submetidos. Vaz (1994: 582) explica que:

Estes trabalhadores aumentavam o contingente de escravos, libertos e imigrantes nacionais e estrangeiros que, chegando à cidade à procura de meios de sobrevivência, buscavam a área central, onde se concentravam moradia e trabalho e fervilhava a vida urbana. Nesta época a estrutura urbana se resumia na aglomeração de atividades e populações no núcleo; só lentamente os transportes coletivos viabilizariam a expansão e o espaço começaria a se especializar, definindo áreas centrais (comerciais), residenciais e industriais. Em resposta à crise habitacional que se agravava, foi no centro que se multiplicaram as moradias possíveis para esta população.

Os textos literários analisados apresentam ainda a figura do proprietário, que vislumbra no aumento populacional oportunidades para o enriquecimento. A partir disso, inicia-se o processo de construção de alojamentos, pensões e estalagens com preços exorbitantes do aluguel, proporcionando grandes rendimentos aos arrendatários. A maioria destes lugares era desprovida de saneamento ou água tratada. Eram ambientes insalubres com casos periódicos de varíola, febre amarela e cólera.

Entende-se que, além daquilo já exposto sobre o autor e sua obra, as narrativas e as descrições eram precisas e fieis à realidade. Os romances de Azevedo apresentam a realidade dos grupos sociais excluídos, mas ao mesmo tempo absorvidos e incorporados ao processo de urbanização do país. Por meio da narrativa, é possível refletir sobre o espaço social proposto por Lefébvre (2000: 8):

Como resultado de forças produtivas e de estruturas, de relações de propriedade entre outras. Ora, o espaço entra nas forças produtivas, na divisão do trabalho; ele tem relações com a propriedade, isso é claro. Com as trocas, com as instituições, a cultura, o saber.

As habitações coletivas descritas por Aluísio Azevedo favorecem o olhar sob vários aspectos da produção do espaço urbano: para aqueles que o construíram; para as transformações desordenadas associadas ao aumento populacional; o aumento do fluxo imigratório (brasileiros 
expulsos do campo e estrangeiros expulsos pela crise populacional na Europa); e a exclusão, pobreza e miséria. Ademais, observa-se as descrições da modernização que inseria nos centros urbanos equipamentos de transporte, indústrias, comércios e serviços.

O autor descreve de forma minuciosa uma paisagem urbana composta por ruas ocupadas pelos carris de ferro, hotéis, universidades, mercados, fábricas, restaurantes e cafés. Exemplo citado em Casa de Pensão é o Hotel Paris, um dos principais hotéis do Rio de Janeiro no século XIX. Uma propriedade suntuosa e imponente, que incorporava a elegância e o bom gosto dos serviços e produtos franceses, cujo restaurante agradava a aristocracia brasileira. Esse lugar aparece na narrativa em Casa de Pensão como um fator que marca a superioridade da cultura europeia em detrimento da nacional. O hotel representa uma identidade urbana para o Rio de Janeiro. Lá, a burguesia se encontrava para apreciar a culinária francesa e discutir a política local.

Em O Cortiço, muitos elementos anunciam a urbanização brasileira por meio de uma paisagem marcada pelos comércios, universidades, fábricas, indústrias e um centro cultural composto por teatros, bibliotecas e livrarias. Esses três últimos lugares citados atraíam a aristocracia e a incipiente burguesia, em luta acirrada pelos agraciamentos da monarquia.

E esses aspectos não são descartados em 0 Mulato. Nessa obra, o romancista descreve a presença de elementos típicos de um centro urbano em formação, como estradas que facilitavam o acesso às propriedades rurais da burguesia e da aristocracia maranhense. A estrada de ferro era destacada pelas personagens como um meio facilitador de mobilidade em direção aos centros econômicos do país, em especial para o transporte do café. Além disso, é notório o surgimento de mercados operados por imigrantes portugueses, que realizavam a logística da indústria cafeeira da província, hoteis que hospedavam os chamados caixeiros e um centro cultural formado por teatros, bibliotecas públicas e livrarias que comercializavam os romances franceses traduzidos para a língua portuguesa.

Apesar de Aluísio Azevedo não ter manifestado nenhum interesse em apresentar uma reflexão sobre as origens do capitalismo e sobre as figuras capitalistas nas cidades em transformação, algumas de suas personagens buscam a acumulação do capital a partir da exploração do trabalho dos indivíduos oriundos de classes sociais inferiores.

Essas personagens foram muito bem construídas pelo autor, a saber: Luís Dias (O Mulato), João Coqueiro e Madame. Brizard (Casa de Pensão) e João Romão (O Cortiço). Essas personagens aparecem como anunciadores dos sujeitos em ascensão mediante a exploração do mais fraco. A avareza e a cobiça são características marcantes desses indivíduos que ambicionam a ascensão 
social, conquistada apenas por Luís Dias e João Romão. Ambos imigrantes portugueses, demonstrando mais uma vez a superioridade da raça branca e europeia.

O primeiro conquista a tão sonhada escalada social por meio do casamento com uma figura importante da aristocracia maranhense. Essa personagem manifesta, antes mesmo do matrimônio, interesse em subjugar e explorar os outros trabalhadores, os induzindo a trabalhar por horas extras, negando qualquer benefício aos empregados e conduzindo os negócios do patrão com projetos para a acumulação do capital; o segundo conquista o título de nobreza (Visconde) mediante a exploração de seus empregados, da escrava Bertoleza (com quem se amasia para evitar pagar pelo seu trabalho), dos moradores e clientes de seu cortiço e armazém, cobrando-lhes alugueis a preços exorbitantes. Mas o que os assemelham enquanto capitalistas é a avareza e a exploração de si mesmo e do outro. Para essas personagens, o dinheiro aparece como forma transcendente do desejo imediato (SANTOS, 2011).

Ressalta-se, porém, que a intenção do escritor não era narrar aspectos característicos do capitalista, mesmo que ele apareça tanto do ponto de vista econômico como social em seus romances. No século XIX a corrente filosófica e científica de grande envergadura no Brasil foi o positivismo. 0 Marxismo só apresentou impacto no país em final do século XIX e início do século XX.

Esses elementos contribuem para a reflexão e a análise da produção do espaço social brasileiro. O que talvez desabone essas leituras, do ponto de vista das correntes filosóficas contemporâneas são o darwinismo e o determinismo social. Deveras, o período em que se circunscrevem esses romances marca a influência dessas teorias no pensamento científico e intelectual brasileiro.

O determinismo social nas obras de Aluísio Azevedo serve até mesmo para justificar 0 surgimento dos lugares insalubres de moradia, a pobreza e a miséria; a violência; e também 0 preconceito racial. Em O Mulato, o protagonista, apesar de apresentar um perfil que aspira toda a superioridade europeia, é visto com desdém, preconceito e ameaça pelos brancos. 0 darwinismo social é observado, na medida em que a narrativa é conduzida por personagens que curvam-se diante da superioridade do branco europeu que recusam-se a aceitação da estratégia de branqueamento, referindo-se aos mestiços por "cabras".

Em Casa de Pensão e O Cortiço essas ideias não são diferentes. No primeiro, o protagonista Amâncio, de família abastada no Maranhão, chega à corte para cursar Medicina, mas logo torna-se vítima de um círculo social degradante na pensão em que mora. Ali, exposto a um ambiente de adultérios, mentiras, avareza, inveja e corrupção, é influenciado, altera seu comportamento, torna-se 
preguiçoso, mentiroso, inclinado a vida desregrada e sem objetivos. O meio condiciona as personagens, tornando-as violentas, culminando na prisão e assassinato de Amâncio.

Já em $O$ Cortiço, há personagens muito emblemáticas e que são centrais nas narrativas para exemplificar a influência do meio, até mesmo, na razão humana. As personagens Pombinha e Jerônimo são arrastados para a degradação moral, ao conviver com sujeitos considerados inferiores, preguiçosos, negligentes, violentos e com personalidade dúbia.

Pombinha, uma moça com educação aristocrática é obrigada a se mudar para 0 Cortiço junto com sua mãe em decorrência da falência de sua família, ali a rapariga recatada e tímida, prometida a um bom casamento (a única salvação de sua dignidade), torna-se prostituta ao ser seduzida e influenciada por sua "madrinha", também entregue a prostituição.

De acordo com as reflexões desenvolvidas a partir do existencialismo sartreano, o meio e a realidade social afetaram a experiência e a emoção de Pombinha. Talvez, ao não ser marcada com tal realidade, assumiria traços de personalidade divergentes da sua vontade primeira. Ao ser seduzida e experienciar sua primeira relação homossexual; assumir-se prostituta; e recusar o casamento imposto ela emancipa-se e ultrapassa a fronteira da puberdade tornando-se mulher responsável por suas atitudes. Sua essência se fez a partir de escolhas próprias. Ao romper com as intransigências e imposições sociais de um espaço patriarcal e machista, onde o homem determina os valores e condições existenciais da sociedade, em especial o lugar da mulher, Pombinha emancipou-se, a sua essência configurou-se a partir dessas experiências.

Jerônimo é outra personagem d'O cortiço que desvirtua-se ao ser condicionado ao meio degradado. 0 imigrante português, ambicioso e trabalhador, chega ao Brasil em busca de melhores condições de vida. Ao não se adaptar à vida no campo, migra para a cidade e sem possibilidades de arcar com o aluguel de uma moradia individual muda-se para o cortiço, local próximo ao trabalho. Porém, entrega-se aos encantos de Rita Baiana que é a metáfora da mulata brasileira, uma personagem comandada pelos seus instintos biológicos, sem pudor e impulsionada pelo desejo sexual. Jerônimo abandona a família e o emprego, torna-se preguiçoso, se entrega aos vícios e a violência, chegando a assassinar o antigo namorado de Rita Baiana por ciúmes.

Para Sartre (1987), ao explicar o comportamento pelo determinismo, o homem é naturalizado, sem poder de decisão e impotente diante do mundo. Por isso, o filósofo utiliza o termo "escolha" para explicar que o homem projeta ser o que deseja usando de sua liberdade. Assim "a escolha é possível, em certo sentido, porém, o que não é possível é não escolher" (1987, p. 17). A liberdade no existencialismo difere-se do seu significado clássico, o qual refere-se ao "livre-arbítrio", isto é, poder 
optar. Para Sartre, a liberdade é mais do que simplesmente optar por fazer ou não algo, envolve a responsabilidade de seus atos (MARQUES, 1998).

A descrição das personagens e a relação destas com o ambiente demonstram o pensamento do autor acerca da produção do espaço social, produzido por atores sociais condicionados ao meio. Identifica-se, portanto, um espaço marcado pela reprodução das ações e comportamentos dos indivíduos. A origem desses sujeitos determina seu lugar na sociedade, bem como o espaço que irá ocupar. Os mulatos, negros e imigrantes não tinham outras opções além de ocupar um ambiente de degradação e miséria. Uma vez ocupando esses mesmos espaços, outras personagens que até então apresentavam determinado perfil psicológico são influenciadas e condicionadas a reproduzir as mesmas ações que as "classes inferiores", contrariando a educação e a personalidade construída ao longo da vida.

Para Sartre (1987), o conflito existencial do homem frente ao meio social constituído por regras e normas, se dá pela necessidade de submeter-se aos parâmetros de moralidade e conduta. $\mathrm{O}$ conflito se intensifica na medida em que o comportamento de um pode afetar toda a comunidade, pois apresenta caráter universal. A pressão, em decorrência da exploração e desigualdade, afeta as experiências humanas promovendo uma ruptura do homem com os códigos sociais e culturais bem aceitos. Portanto, as experiências positivas ou negativas podem afetar os atos, mas o meio e as "más companhias" são questões de escolha.

Aluísio Azevedo se contradiz sobre o darwinismo social ao demonstrar, por meio das personagens negras que buscaram relacionamentos com uma classe superior - 0 europeu branco -, que a miscigenação como uma tentativa de melhoramento da raça ou branqueamento não é bem sucedida, de forma que, uma vez negro, pobre e excluído para sempre assim o será. O círculo vicioso promoveria, portanto, a reprodução e o crescimento das mazelas sociais traduzidas em espaços de miséria, exclusão e desigualdade. Porém, sua personagem central em O Mulato consegue romper com tais paradigmas em outra sociedade, a europeia, onde o indivíduo mestiço, além de bem aceito, é respeitosamente tratado como doutor.

\section{Considerações Finais}

Os romances de Aluísio Azevedo concentram na descrição dos grupos sociais transgressores, na miscigenação do povo brasileiro, da imigração, a escala na pirâmide social, os operários, trabalhadores e escravos que movem a cidade por meio de seu trabalho. $O$ espaço urbano é palco para a encenação de uma identidade nacional, e das diversas facetas do seu povo. 
As ações sociais e políticas podem ocorrer também fora dos espaços institucionais, podem ser revelada por meio das manifestações artísticas, como o caso das obras literárias. A ação política de Aluísio Azevedo é consubstanciada à revelia do positivismo e do naturalismo, que revelam-se antiquadas no decorrer do século XXI, mas para aquele momento histórico eram as únicas fontes de explicações para os problemas políticos, econômicos e sociais do país. Mesmo, sendo norteado por ideias pessimistas, e por ora preconceituosas, é louvável o exposto pela narrativa, tendo em vista o contexto histórico no qual foi elaborada.

Nesse artigo não há a concentração em se fazer um estudo comparativo entre o modelo de sociedade brasileira do século XIX e a contemporânea, mas ao refletir sobre essa possibilidade, empreende-se a ideia de que as pensões/cortiços e sobrados coexistem nos modelos modernos de cidade. Ainda é possível encontrar nos grandes centros urbanos as representações dessas formas de habitações que representam a desigualdade, a exclusão e a criminalização.

As favelas que desembocam em avenidas que conduzem aos bairros arborizados e emparelhados de prédios suntuosos e imponentes da burguesia, que outrora aparecia metaforicamente no sobrado do burguês Miranda (O Cortiço), vizinho dos moradores d'O Cortiço, que buscava meios de expulsar dali os operários e trabalhadores que nada combinavam com a ostentação de sua casa. Essa personagem se fosse hoje construída, conseguiria expulsar dali os empregados, os realocando nas favelas atuais.

Atualmente, a lógica de convivência entre ricos e pobres, explorador e explorado limita-se aos meios de produção do mercado capitalista, sob a figura do patrão e do empregado. Os bairros periféricos expressam um novo modelo de desenvolvimento, modernidade e civilização, onde os pobres se escondem para não estragar a beleza dos espaços dos ricos.

Mas o que mais chama a atenção na leitura e análise destas três obras é a colocação do homem como um ser passível e propício ao condicionamento. $\mathrm{O}$ espaço urbano é construído por meio da contradição social, em que o rico e pobre ambos vivendo em um mesmo espaço, não se misturam. O pobre é mais favorável a adaptação ao meio degradado, enquanto o rico, em especial o branco europeu, está acima da possibilidade de juntar-se e imitar o comportamento dos operários, submissos e subjugados. É contraditório essa proposição do autor, uma vez que ao estarem próximos a relação de influência deveria ser recíproca. E pela superioridade europeia e branca, estes padrões que deveriam exercer maior força na polaridade "inferior - superior", ou seja, o rico com educação aristocrática e bem sucedido deveria ser capaz de influenciar os comportamentos e ações dos inferiores. 
Ao narrar ações em que as personagens condicionadas ao meio cometem assassinatos, entregam-se a prostituição e a loucura influenciados pela miséria e mazelas sociais, Aluísio Azevedo desconsidera o poder de escolha e decisão desses indivíduos, isto é, a sua essência construída por meio de experiências e emoções. Para Sartre (1987), o homem que justifica-se por suas paixões e pelo meio, age de má-fé, encontra-se na mentira dos engajamentos sociais.

Propor o estudo das obras de ficção a partir dos conceitos de duas correntes filosóficas divergentes em tempo e espaço é fazer uma leitura interdisciplinar, é identificar nuances que promovem a construção do saber geográfico a partir de experiências e diálogos mais amplos e que extrapolam o conhecimento específico de uma disciplina acadêmica, fazendo dialogar três propostas de explicações para a realidade.

Portanto, 0 interesse em trazer o diálogo entre essas disciplinas acadêmicas - Literatura, Geografia e Filosofia -, com um olhar holístico e crítico acerca das relações entre essas áreas do conhecimento, é conceber a complementação e a produção de novas discussões e novas perspectivas para ampliar os horizontes na busca dialógica (FEITOSA; MORAES; COSTA, 2012: 185).

A Geografia Humanista e Cultural, que em suas bases teóricas e metodológicas preocupa-se em explicar o campo da existência e experiências no espaço, possibilita a leitura deste, a partir do homem e da sua leitura e visão de mundo. A aproximação destas disciplinas propostas no texto permite "identificar elementos 'reais' na descrição dos espaços sociais.

Portanto, o que se propõe com a leitura de romances do naturalismo brasileiro é ampliar a abordagem acerca das representações e percepções acerca dos lugares e de suas paisagens. Ademais, as leituras das descrições de Aluísio de Azevedo possibilitam o entendimento de elementos que ultrapassam apenas o visível, mas que também caracterizam e singularizam os espaços como a cultura sob as diversas manifestações do povo brasileiro.

\section{Referências}

ACADEMIA BRASILEIRA DE LETRAS (ABL). Biografia. Disponível em: http://www.academia.org.br/academicos/aluisio-azevedo/biografia. Acesso em 24 de julho de 2015. ALMEIDA, Rodrigo Estramanho de. Crítica, romance e positivismo em Aluísio Azevedo. In: XV Congresso Brasileiro de Sociologia. Curitiba, PR: 2011. Disponível em: www.sbsociologia.com.br/portal/index.php?option=com_docman\&task=doc_download\&gid=2268\&ltemi $\mathrm{d}=171$. Acesso em 27 de julho de 2015.

ALONSO, Angela. Crítica e Contestação: o movimento reformista da geração 1870. In RBCS, vol. 15 , $\mathrm{n}^{\circ}$ 44, outubro, 2000. Disponível em http://www.scielo.br/pdf/rbcsoc/v15n44/4146.pdf. Acesso em 19 de julho de 2015.

AZEVEDO, Aluísio. O Mulato. Ministério da Cultura: Fundação Biblioteca Nacional. E-book. Disponível em: http://www.ebooksbrasil.org/adobeebook/omulato.pdf. Acesso em 12 de janeiro de 2015.

AZEVEDO, Aluísio. Casa de Pensão. São Paulo: Editora Ática, 1989. 
AZEVEDO, Aluísio. O cortiço. Rio de Janeiro: Editora Livreiro Editor Garnier, 1880.

BARDIN, Laurence. Análise de Conteúdo. São Paulo: Editora Edições 70, 2011.

COUTINHO, Afrânio. A Literatura no Brasil. São Paulo: Editora Global, 2004.

DIAS, Júlio César Tavares. O ambiente do realismo literário no Brasil. In Revista de Letras da Universidade Católica de Brasília. Vol. 3, $n^{0} 1 / 2$ - Ano III, dez./2010. Disponível em http://portalrevistas.ucb.br/index.php/RL/article/viewFile/1836/1312. Acesso em 17 de julho de 2015.

FEITOSA; Márcia M. M.; MORAES, Cláudia Letícia G.; COSTA, Janete de Jesus. O entrelaçamento de fios entre a geografia e a literatura: a construção de um saber múltiplo. Revista NUPEM, Campo Mourão, v. 4, n.6, 2012.

LEFEBVRE, Henri. A produção do espaço. Paris: Editora Anthropos, 2000.

LIMA, Luis Adriano. A identidade nacional e as escolas literárias. In Literatura e Cinema - 0 Anagrama. 2012, s/p. Disponível em http://www.oanagrama.com/2012/04/identidade-nacional-e-as-escolas.html. Acesso em 15 de agosto de 2015.

MARANDOLA JR., Eduardo. Humanismo e arte para uma geografia do conhecimento. In Geosul, v. 25, n. $\quad 49,2010$. Disponível em https://periodicos.ufsc.br/index.php/geosul/article/view/21775230.2010v25n49p7 Acesso 21 de abril de 2014.

MARQUES, Ilda. Sartre e o Existencialismo. In Revista Eletrônica FUNREI. Metanoia: São João DelRei, n. 1, p. 75-80, jul. 1998. Disponível em: http://www.ufsj.edu.br/portalrepositorio/File/revistalable/numero1/ilda9.pdf. Acesso em 18 de dezembro de 2015.

MOREIRA, Jorgeanny de Fátima R. Paisagens Culturais e Lugar do Povo Kalunga do Engenho II em Cavalcante, Goiás: cotidiano e festas. Jundiaí, São Paulo: Editora Paco Editorial, 2016.

SANTOS, Vivaldo Andrade dos. Uma leitura econômica de O Cortiço, de Aluísio Azevedo. In Revista IEB, n 54, 2011, set./mar., p. 53-66. Disponível em: http://www.scielo.br/pdf/rieb/n54/a05n54.pdf. Acesso em 27 de julho de 2015.

SARTRE, Jean-Paul. Esboço para uma teoria das emoçõ. São Paulo: Editora L\&PM, 1987.

SARTRE, Jean-Paul. L'Existentialisme est un Humanisme. Paris: Editora Les Éditions Nagel, 1970.

SERÉN, Maria do Carmo. Rodrigues de Freitas e o Darwinismo Social. In ALMODOVAR, Antônio; ALVES, Jorge Fernandes; GARCIA, Maria do Pilar (Org.). Rodrigues de Freitas: a obra e os contextos. Actas de Colóquio. Coimbra: CLC-FLUP, 1997. 292 p.

SILVA, Felipe Antonio Ferreira da. Uma análise sobre a relevância do espaço como personagem na obra O Cortiço, e Aluísio de Azevedo. In Revela: periódico de divulgação científica da FALS. Ano IV n VIIII - Jun./2010. ISSN: 1982-646X.

VASSALO, Lígia. Cortiço e a cidade do Rio de Janeiro. In Ipotesi - Revista de Estudos Literários. V. 4, $n^{0}$ 1., 2009. p. 103-110. Disponível em http://www.ufff.br/revistaipotesi/files/2009/12/Corti\%C3\%A7o-ea-cidade-do-RJ1.pdf. Acesso em 27 de julho de 2015.

VAZ, Lilian Fessler. Dos cortiços às favelas e aos edifícios de apartamentos - a modernização da moradia no Rio de Janeiro. In Análise Social. Vol XXIX (127), 1994 (3º), pp. 581-597.

VERISSIMO, Érico. Breve História da Literatura Brasileira. São Paulo: Editora Globo, 1995.

ZOLA, Émile. O romance experimental e o naturalismo no Teatro. São Paulo: Editora Perspectiva, 1979. 